\title{
Effects of intersite dependence of nested catchment structures on probabilistic regional envelope curves
}

\author{
B. Guse ${ }^{1,2}$, A. Castellarin ${ }^{3}$, A. H. Thieken ${ }^{1,4}$, and B. Merz ${ }^{1}$ \\ ${ }^{1}$ Deutsches GeoForschungsZentrum GFZ, Section Hydrology, Potsdam, Germany \\ ${ }^{2}$ Center for Disaster Management and Risk Reduction Technology (CEDIM), Karlsruhe, Germany \\ ${ }^{3}$ Dipartimento di Ingegneria delle Strutture, dei Trasporti, delle Acque, del Rivelamento, del Territorio (DISTART), \\ Università di Bologna, Bologna, Italy \\ ${ }^{4}$ alpS - Centre for Natural Hazards and Risk Management, University of Innsbruck, Innsbruck, Austria
}

Received: 19 March 2009 - Published in Hydrol. Earth Syst. Sci. Discuss.: 31 March 2009

Revised: 11 August 2009 - Accepted: 9 September 2009 - Published: 29 September 2009

\begin{abstract}
This study analyses the intersite dependence of nested catchment structures by modelling cross-correlations for pairs of nested and unnested catchments separately. Probabilistic regional envelope curves are utilised to derive regional flood quantiles for 89 catchments located in Saxony, in the Southeast of Germany. The study area has a nested structure and the intersite correlation is much stronger for nested pairs of catchments than for unnested ones. Pooling groups of sites (regions) are constructed based on several candidate sets of catchment descriptors using the Region of Influence method. Probabilistic regional envelope curves are derived on the basis of flood flows observed within the pooling groups. Their estimated recurrence intervals are based on the number of effective sample years of data (i.e. equivalent number of uncorrelated data). The evaluation of the effective sample years of data requires the modelling of intersite dependence. We perform this globally, using a cross-correlation function for the whole study area as well as by using two different cross-correlation functions, one for nested pairs and another for unnested pairs. In the majority of the cases, these two modelling approaches yield significantly different estimates for the effective sample years of data, and therefore also for the recurrence intervals. The reduction of the recurrence interval when using two different cross-correlation functions is larger for larger pooling groups and for pooling groups with a higher fraction of nested catchments. A separation into nested and unnested pairs of catch-
\end{abstract}

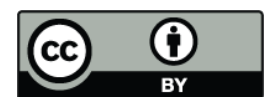

Correspondence to: B. Guse (bguse@gfz-potsdam.de) ments gives a more realistic representation of the characteristic river network structure and improves the estimation of regional information content. Hence, applying two different cross-correlation functions is recommended.

\section{Introduction}

The estimation of flood quantiles is a major topic in hydrologic research and engineering practise. Due to the uncertainty in the estimation of flood discharges with large recurrence intervals $T$ (e.g. $T>100$ years) by an at-site flood frequency analysis, several gauges may be pooled together in a pooling group following the principle "trading space for time" (e.g. Stedinger et al., 1993; Robson and Reed, 1999). Therefore, it is assumed that analysis results, e.g. results of a regional flood frequency analysis (RFFA), are valid for all gauges of a specific pooling group. RFFA aims at improving the estimation of flood quantiles by using the larger number of flood data. However, an improvement can only be reached by increasing the effective sample years of data (i.e. the number of independent observations). The increase in the effective sample years of data when adding a new site to a pooling group can be assessed by considering the intersite correlations or cross-correlations among all gauges in a pooling group (Matalas and Langbein, 1962).

A pooling group comprises catchments of similar hydrologic behaviour. In flood regionalisation studies, fixed homogeneous regions are traditionally used, whereby each site is explicitly assigned to one region, e.g. through cluster analysis (e.g. Acreman and Sinclair, 1986; Nathan and McMahon,

Published by Copernicus Publications on behalf of the European Geosciences Union. 
1990; Rao and Srinivas, 2006). In contrast, the Region of the Influence (RoI) approach (e.g. Burn, 1990a, b; Zrinji and Burn, 1994) constructs a separate pooling group for each site in the region under study.

Several methods and many studies on regional flood frequency analysis have been presented (e.g. Cunnane, 1988; GREHYS, 1996a, b; Robson and Reed, 1999; Merz and Blöschl, 2005; Ouarda et al., 2008). A common application is the widely used index flood approach, which assumes that a regional growth curve is representative for all sites of a homogeneous region. The at-site flood quantiles vary only in the scale factor index flood (e.g. Dalrymple, 1960; Stedinger and Lu, 1995; Robson and Reed, 1999). Linear regression models relate catchment descriptors (e.g. drainage area, precipitation indices) to a predefined flood quantile (e.g. Rosbjerg and Madsen, 1995; Kroll and Stedinger, 1998; Robson and Reed, 1999; Reis et al., 2005). Recently, geostatistical methods (e.g. Top-Kriging) were introduced to regionalise flood quantiles (Merz and Blöschl, 2005; Skoien et al., 2006).

Regional envelope curves (REC) are a variant of linear regression models which only use the size of the drainage area to estimate the maximum flood discharge (e.g. Crippen and Bue, 1977; Herschy, 2002). A shortcoming of the traditional REC method is, however, that no recurrence interval can be assigned to the maximum discharge. Therefore, Castellarin et al. (2005) proposed the method of probabilistic regional envelope curves (PREC), which enhance the traditional REC approach with a probabilistic interpretation. The method of PREC requires a pooling group, which fulfils the homogeneity criteria of the index flood method. The recurrence interval of PREC is directly related to the effective sample years of data. Hence, its calculation algorithm explicitly considers the effect of cross-correlated sites in a pooling group of data.

Several studies have demonstrated the relevance of intersite correlation for regional flood estimates (e.g. Stedinger, 1983; Hosking and Wallis, 1988; Madsen and Rosbjerg, 1997a; Vogel et al., 2001). Matalas and Langbein (1962) introduced the concept of regional information content to determine the effect of intersite correlation within flood sequences. The regional information content expresses the number of independent discharge observations. The authors showed that the variance of the regional mean increases for cross-correlated sites.

Kuczera (1983) assessed that a low number of observations and the presence of intersite correlation leads to a larger uncertainty of an empirical Bayes estimator. Stedinger (1983) demonstrated that the variance of the regional variance and skewness increases due to intersite correlation. Hosking and Wallis (1988) pointed out that cross-correlation among sites leads to less accurate estimates of regional flood quantiles; however, the influence of regional heterogeneity is more significant. Applying hydrologic linear regression models, Stedinger and Tasker (1985) introduced intersite correlation by extending the weighted least square (WLS) to the generalised least square (GLS) method, which explicitly considers the impact of cross-correlated sites. Several studies confirmed that the GLS estimator outperforms the WLS or the ordinary least squares (OLS) estimator for the application of linear regression models in the case of cross-correlated sites (see e.g. Stedinger and Tasker, 1985, 1986; Kroll and Stedinger, 1998; Reis et al., 2005).

The impact of intersite correlation on regional estimates was analysed for Partial Duration Series by Madsen and Rosbjerg (1997a, b) and for Annual Maxima Series by Kjeldsen and Rosbjerg (2002) and Kjeldsen and Jones (2006). Madsen and Rosbjerg (1997a) pointed out that intersite correlation needs to be considered to accurately assess the uncertainty of the regional estimator. It has recently been demonstrated by Castellarin et al. (2008) that intersite correlation affects the heterogeneity measure of Hosking and Wallis (1993), which estimates the hydrologic heterogeneity of a region.

The distance between two catchments is generally assumed to be the most important factor for intersite correlation resulting in different cross-correlation models. In these models, the correlation coefficient decreases as a function of the distance between the catchments (see e.g. Tasker and Stedinger, 1989; Troutman and Karlinger, 2003).

The effects of the river network structure and mutual location of catchments were considered by Troutman and Karlinger (2003). They pointed out that peak flows between nested catchments, i.e. catchments along the same stream, are more correlated than peak flows between unnested catchments. In terms of flood regionalisation methods Skoien et al. (2006) demonstrated the better performance of TopKriging, which considers the effect the river network structure, in comparison to a traditional Ordinary Kriging approach, which is based only on the distances between the catchments.

Castellarin et al. (2005) developed an empirical function by using a Monte-Carlo simulation to reveal the reduction of the overall sample years of data in a pooling group due to intersite correlation, and to obtain the effective number of sample years of data for estimating the recurrence interval of a PREC. This is equivalent to the number of independent data associated with the concept of information content by Matalas and Langbein (1962). Castellarin (2007) examined the accuracy of PREC flood quantiles by comparing different cross-correlation functions for an Italian data set. Owing to the small number of nested catchments, different crosscorrelation functions for nested and unnested catchment relationships were not estimated.

In this study, we assess the impact of different approaches to model regional cross-correlation structure with respect to their impact on the effective number of observations and the recurrence interval of probabilistic regional envelope curves (PREC). First, a global approach is considered, in which the cross-correlation function is identified for the whole study area. Second, the method of PREC as described by Castellarin et al. (2005) and Castellarin (2007) is extended by 
deriving two different cross-correlation functions, one for nested pairs of catchments and one for unnested ones. While applying both approaches we did not vary any other aspect of flood regionalisation (e.g. selection of catchment descriptors, pooling method, etc.), since our investigation mainly focuses on the correlation structure for nested and unnested pairs of catchments. Significant factors, which influence the effect of intersite correlation on PREC, are determined. The study region, Saxony in south-eastern Germany, includes several pairs of nested catchments and enables us to examine in detail the effect of nested catchment structures on PREC flood quantiles, whose importance was not adequately acknowledged in previous studies.

\section{Methods}

\subsection{Regional information content and number of effective observations}

The regional information content (IC) can be defined as the ratio of the effective sample years of data $n_{\text {eff }}$ to the total sample years of data $n$. The effective sample years of data represents the equivalent number of independent observations within a pooling group (Eq. 1).

$\mathrm{IC}=\frac{n_{\text {eff }}}{n}$

The core idea of regional information content (Matalas and Langbein, 1962) is that a correlated site gives a lower degree of additional information to the site being studied than an uncorrelated site. Hence, the additional information decreases for a higher intersite correlation. An IC of 1 means that these sites are completely uncorrelated (independent), implying that the total flood sequence gives additional information $\left(n_{\mathrm{eff}}=n\right)$. In contrast, a small value of IC indicates that there is only low additional information within the time series (Matalas and Langbein, 1962).

On the basis of the regional information content, Castellarin et al. (2005) and Castellarin (2007) estimated the exceedance probability of a regional envelope curve. The effective sample years of data $n_{\text {eff }}$, hereafter also referred to as the number of effective observations, were calculated by reducing the total sample years of the AMS of all gauges in two steps (Castellarin, 2007). First, the intersite correlation between the different AMS was modelled as a function of the distance between the catchment centroids. Second, the results of the cross-correlation function were used to estimate the number of effective observations.

(1) A regional cross-correlation function (Eq. 2), from Castellarin, 2007), proposed by Tasker and Stedinger (1989), was applied, which estimates the cross-correlation as a function of the distance.

$\rho_{i, j}=\exp \left(-\frac{\lambda_{1} d_{i, j}}{1+\lambda_{2} d_{i, j}}\right)$ $d=$ distance between catchment centroids, $\rho=$ correlation coefficient by Pearson, $\lambda_{1}, \lambda_{2}=$ parameters, $i, j=$ index denoting pairs of catchments.

Therefore, empirical cross-correlation coefficients between the AMS were related to the distances between the catchment centroids. By using catchment centroids the river network structure is incorporated in the distance calculation (e.g. Troutman and Karlinger, 2003). The parameters $\lambda_{1}$ and $\lambda_{2}$ of the cross-correlation function were fitted by a weighted optimisation, in which empirical coefficients were weighted proportionally to the length of the overlapping time series.

(2) The number of effective observations was calculated by an empirical relationship, which incorporated the theoretical average cross-correlation values from Eq. (2). The data set of a specific pooling group comprises $M$ times AMS with a variable length, but not more than $Y$ years. The length of the AMS varies due to missing observations or different observations periods. In a first step, all years $n_{1}$ with only one observation among the $M$ discharge time series were considered separately. In these years, all other (M-1) gauging stations have no discharge measurements. The $n_{1}$ observations are certainly effective, because there is only one discharge value within the pooling group for this year (Castellarin, 2007).

After this, the $Y-n_{1}$ remaining years were analysed. These years were split into $Y_{\text {sub }}$ subsets with $Y_{\text {sub }} \leq\left(Y-n_{1}\right)$. In each of these subsets (denoted as $s$ ), there were $L_{s}$ flood sequences with an equal length of years $l_{s}$ with $L_{s} \leq M$. The number of effective observations of a subset $n_{\text {eff, } s}$ was calculated for each subset $s$ separately. Then, the numbers of effective observations $n_{\text {eff, } s}$ were summed up for all subsets. In the last step, the number of effective sample years of data $n_{\text {eff }}$ comprises the $n_{1}$ years with one observation and the sum of the numbers of effective observations $n_{\text {eff, } s}$ for all $Y_{\text {sub }}$ subsets. The number of effective observations was calculated by an empirical relationship derived by Castellarin et al. (2005) and Castellarin (2007) from Monte-Carlo simulations (Eq. (3), adopted from Castellarin, 2007).

$$
\begin{gathered}
n_{\mathrm{eff}}=n_{1}+\sum_{s=1}^{Y_{\text {sub }}} n_{\mathrm{eff}, s}=n_{1}+\sum_{s=1}^{Y_{\text {sub }}} \frac{L_{s} l_{s}}{1+\left[\overline{\rho^{\beta}}\right]_{L_{s}}\left(L_{s}-1\right)} \\
\text { with } \beta:=1.4 \frac{\left(L_{s} l_{s}\right)^{0.176}}{\left[\overline{\left.(1-\rho)^{0.376}\right]_{L_{s}}}\right.},
\end{gathered}
$$

where the term []$_{L_{s}}$ denotes that the average values $\overline{\rho^{\beta}}$ and $\overline{(1-\rho)^{0.376}}$ are calculated for the $L_{s}$ annual flood sequences.

It becomes apparent that different parameter values for $\lambda_{1}$ and $\lambda_{2}$ directly affect the results of Eq. (2) and therefore also of Eq. (3). Consequently, the number of effective observations $n_{\text {eff }}$ is affected by using different parameter sets for the cross-correlation function. Equation (3) illustrates that the magnitude of $n_{\text {eff }}$ depends on the size of the available data set and their cross-correlation characteristics. 


\subsection{Probabilistic regional envelope curves}

The calculation of the number of effective sample years of data is a fundamental step towards the estimation of the exceedance probability of a regional envelope curve. A regional envelope curve (REC) is determined by relating all floods of record $Q_{\mathrm{FOR}}$ normalised by the drainage area (A) to A (Eq. (4), adopted from Castellarin, 2007). The flood of record is the largest discharge of each time series.

$\log \left(\frac{Q_{\mathrm{FOR}}}{A}\right)=a+b * \log (A)$

$a=$ intercept of REC, $b=$ slope of REC.

The concept of the probabilistic regional envelope curve (PREC) requires that two basic assumptions are fulfilled: firstly, PREC is based on the index flood hypothesis. The index flood method (Dalrymple, 1960) requires that all selected flood series constitute a homogeneous region. These flood series are identically distributed, i.e. have the same growth curve, except for the scale parameter, the index flood (e.g. Robson and Reed, 1999). In this study, the mean of the AMS was used as index flood. Secondly, there is a scaling of the index flood $\mu_{X}$ to the drainage area (A) (Eq. (5), from Castellarin et al., 2005). The index flood depends on the drainage area alone.

$\mu_{X}=C * A^{b+1}$

A regional envelope curve can be derived in two steps. First, the slope $b$ is estimated by a regression analysis (orange line in Fig. 1). The second step is a parallel upshift of the regression line up to the intercept $a$. Then all floods of record are bounded by REC (blue line in Fig. 1) (Castellarin et al., 2005).

Since the PREC method is based on the index flood hypothesis, the derivation of a pooling group which fulfils the homogeneity criteria of the index flood hypothesis is an essential step in the PREC concept. In this work, PREC was applied for all regions with at least four sites.

The core idea of PREC is the assignment of an exceedance probability to a REC. The exceedance probability is estimated for that particular data pair (i.e. the unit flood of record and associated drainage area) which determines the intercept of REC. This is the exceedance probability of the largest unit flood of record in the region.

For this purpose, the plotting position of the maximum unit flood of record was used, which was determined by the number of effective observations $n_{\text {eff }}$ (Eq. 3) and the Hazen function (Eq. (6), from Castellarin, 2007).

$T=2 * n_{\mathrm{eff}}$

Castellarin (2007) showed that the Hazen function is a suitable quantile unbiased plotting position when the Generalised Extreme Value (GEV) distribution is an adequate parent distribution. The suitability of the GEV for this study

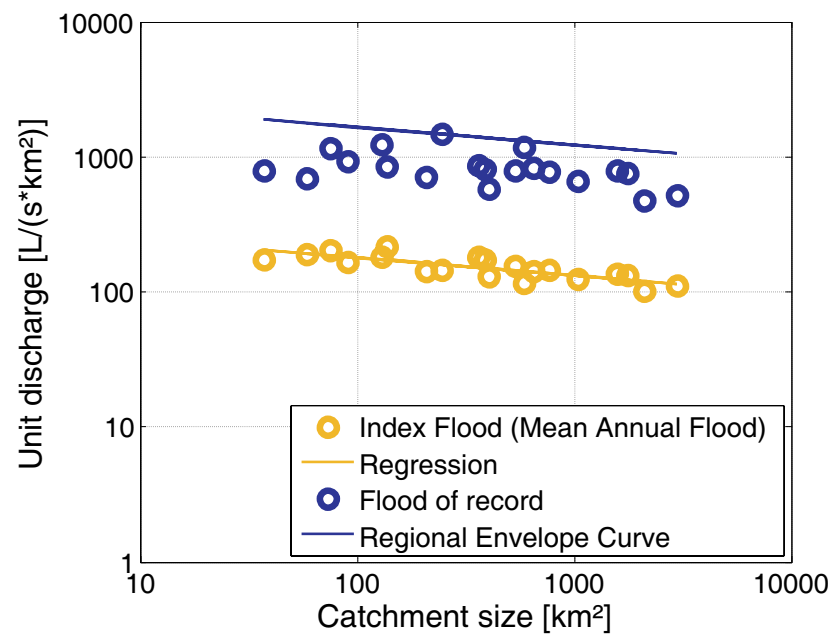

Fig. 1. Example of a Regional Envelope Curve (REC).

is discussed in Sect. 3. Equation (6) implies that the reduction effect of intersite correlations on $n_{\text {eff }}$ directly affects the estimation of $T$. The recurrence interval $T$, i.e. the inverse of the exceedance probability, is derived for the entire pooling group and therefore is identical for all gauges. Its validity is restricted to the range of the catchment size within the pooling group, i.e. from the smallest to the largest catchment size. Thus, the use of different parameter values for the cross-correlation function affects $T$ in the same way as $n_{\text {eff }}$. We referred to Castellarin et al. (2005), Castellarin (2007) and Castellarin et al. (2007) for more detailed information of the PREC concept.

\subsection{Pooling scheme}

The method of PREC is based on the index flood hypothesis. This implies the need of pooling groups fulfilling the homogeneity criteria of the index flood method. In this case, the PREC concept is valid for all sites of the pooling group. This study is tailored to assess the impact of different approaches to the modelling of the regional cross-correlation structure on several PREC applications. For this purpose several pooling groups, derived using the Region of Influence (RoI) method, are needed. We derived several candidate sets of catchment descriptors instead of one "best subset", because the use of a "best subset" neglects that different subsets of catchment descriptors could have a similar performance. The pooling groups were constructed by the following six steps:

(1) we selected meaningful predictor variables which were standardised (mean $=0$, std $=1$ ) to allow a comparison between them. We combined the standardised catchment descriptors to create all possible subsets with one, two and three catchment descriptors.

(2) We defined only those subsets of catchment descriptors as candidate sets, which had the largest correlation to 
the empirical unit index floods. A correlation coefficient of 0.6 was selected as threshold. Index flood values were used as explained variable because the PREC method is based on a scaling of the index flood values with the drainage area (see Eq. 5).

(3) We then checked all candidate sets with three catchment descriptors on redundancy compared to the selected subsets of two catchment descriptors. We only maintained candidate sets with three catchment descriptors which led to a larger proportion of explained variance (higher correlation coefficient).

(4) We checked all subsets on multicollinearity by the Variance Inflation Factor (VIF) (Hirsch et al., 1992) and removed them if the VIF was larger than five.

(5) Each remaining candidate set was used to derive a Region of Influence (RoI) (Burn, 1990a, b). The RoI method identifies a specific pooling group of sites (region in the widest sense) for each gauge (site of interest). The rationale behind this approach is that the specific hydrologic conditions of the site of interest are considered to select hydrologically similar gauges. Instead of the geographical distance, a physiographical space was formed by the catchment descriptors of a selected subset. By selecting sites close to the site of interest in the physiographical space, adequate sites were determined for constructing a RoI. We used the Euclidean distance in the physiographical space between the sites to evaluate their similarity to the site of interest (Burn, $1990 \mathrm{a}, \mathrm{b})$. RoIs were formed by assessing three different thresholds $(0.5,1$ and 2$)$ of the Euclidean distance. The different thresholds reflect the trade-off between the size and the regional homogeneity of a pooling group (e.g. Burn, 1990a; Castellarin et al., 2001). In a preliminary analysis, another RoI variant was also applied as proposed by Gaál and Kyselý (2009). Thereby, we started with a RoI which includes the ten most similar sites. The size of the RoI was determined by iteratively adding sites to the RoI until the threshold of $\mathrm{H}_{1}<2$ was exceeded or in the case of an initially heterogeneous RoI by removing sites until the $\mathrm{H}_{1}$-test falls below the threshold (step-wise approach) (see e.g. Zrinji and Burn, 1994; Castellarin et al., 2001; Gaál and Kyselý, 2009). Since we found no significant variations in the results, we only report here the results of the first RoI variant.

(6) The pooling groups constructed by RoI were tested on homogeneity by the heterogeneity measure (H-test) of Hosking and Wallis (1993). The H-test compares the regional heterogeneity of a pooling group in terms of the variability of L-moment ratios with simulated synthetic time series calculated by a Monte-Carlo simulation. The $\mathrm{H}_{1}$-test focuses on the sample variability of the L-coefficient of variation (L-CV). Since synthetic time series generated in the test are independent by definition, intersite correlation introduces some bias in the $\mathrm{H}_{1}$-test results (Castellarin et al., 2008). Hosking and Wallis (1997) mentioned that a very low value of their heterogeneity measure $\left(\mathrm{H}_{1}<-2\right)$ indicates a high intersite correlation. All regions with $\mathrm{H}_{1}$-values lower than 1 are acceptably homogeneous and with $\mathrm{H}_{1}$-values between 1 and 2 are possibly heterogeneous (Hosking and Wallis, 1997). This means that a modification of the region is not required or optional, respectively. The $\mathrm{H}_{1}$ test was performed with the hw.test (Viglione, 2008, implemented in $\mathrm{R}$ ). We used each RoI with $\mathrm{H}_{1}<2$ to form a pooling group and to derive a PREC. Hence, the number of PREC realisations was identical with the number of homogeneous RoIs.

\subsection{Application and interpretation of different cross- correlation functions}

The number of effective observations was calculated using the cross-correlation function (see Eq. 2) with separately optimised parameter sets. In a first approach, the number of effective observations (see Eq. 3) was calculated by using one cross-correlation function for the whole study area (global approach, termed: $n_{\mathrm{eff}, G}$ ). Second, the cross-correlation function was applied with different parameter sets for nested and unnested catchments (nested approach, termed: $n_{\text {eff, } N}$ ). The parameter set for nested structures was used for the pairs of catchments which are in an upstream-downstream relationship, termed $P_{N}$. For all of the others, the unnested parameter set was employed. The numbers of the effective observations $n_{\text {eff, } G}$ and $n_{\text {eff, } N}$ were compared for the same pooling groups. Therefore, the information content (IC), i.e. the fraction of the effective observations $n_{\text {eff }}$ to the total observations n, was calculated according to Eq. (1) for the global case $\left(\mathrm{IC}_{G}\right)$ and the nested-unnested $\left(\mathrm{IC}_{N}\right)$ approach. In a next step, the ratio $R_{N}$ was calculated as a function of the differences between $n_{\mathrm{eff}, N}$ and $n_{\mathrm{eff}, G}$ using $n_{\mathrm{eff}, G}$ as reference (Eq. 7).

$R_{N}=\frac{n_{\mathrm{eff}, N}-n_{\mathrm{eff}, G}}{n_{\mathrm{eff}, G}} * 100=\frac{T_{N}-T_{G}}{T_{G}} * 100$

The ratio $R_{N}$ facilitates the interpretation of the influence of the different parameter sets on the number of effective observations. Furthermore, the study focuses on the recurrence interval $T$ of PREC, which, according to Eq. (6), is twice as high as the number of effective observations. Consequently, the ratio $R_{N}$ is identical when using $T$ instead of $n_{\text {eff }}$ (Eq. 7).

The effect of the nested structure on $T$ was investigated by calculating a degree of nesting $D_{N}$ (Eq. 8). It is defined as 


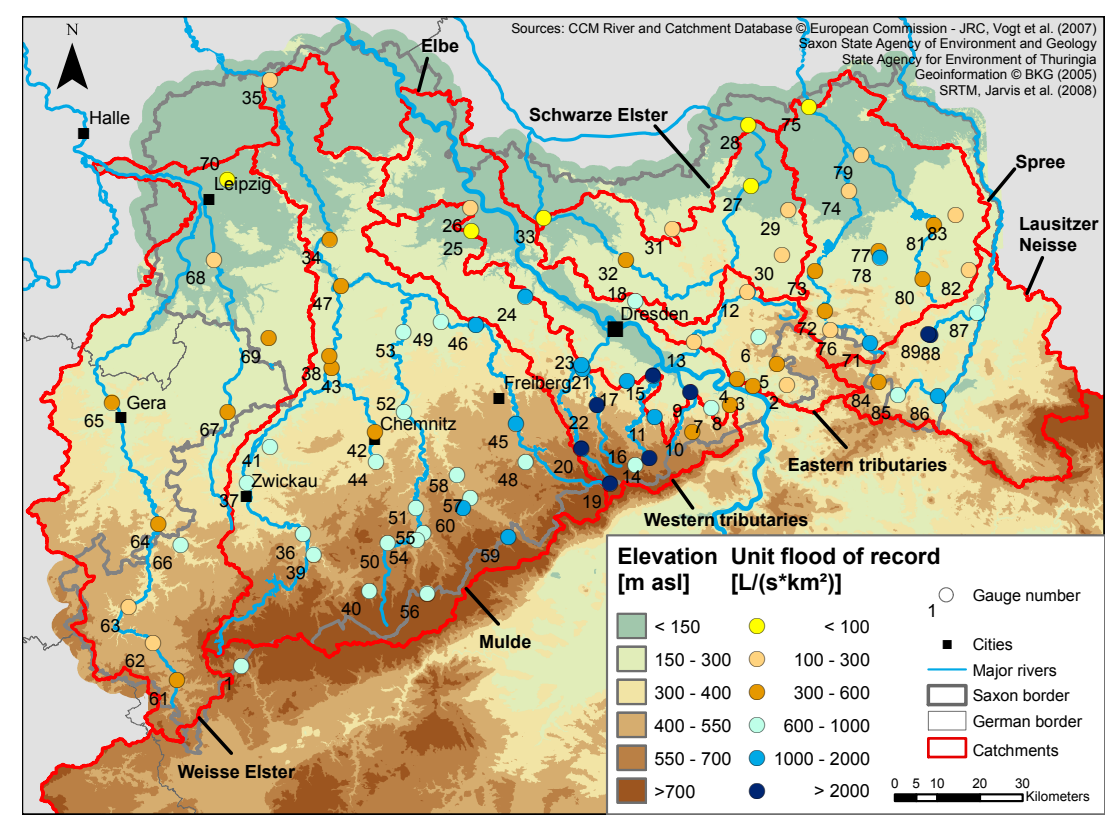

Fig. 2. Elevation and gauging stations in Saxony, Germany. The colour scale indicates the unit flood of record at each gauge.

the ratio between nested catchment pairs $P_{N}$ and all pairs of catchments $P$ in a pooling group.

$D_{N}=\frac{\sum_{k=1}^{Y-n_{1}} \frac{P_{N_{k}}}{P_{k}}}{Y-n_{1}}$

The nested catchment structure was estimated separately for each year. The years with a single observation $\left(n_{1}\right.$ in Eq. 3$)$ were not considered in this approach. Ultimately, the mean degree of nesting $D_{N}$ for the $Y-n_{1}$ years (see Sect. 2.1) was calculated for each RoI.

Finally, since the estimation of flood quantiles derived by PRECs is affected by intersite correlation (through the different parameter sets of the cross-correlation function), but also by regional heterogeneity (through the threshold adopted for the heterogeneity measure $\mathrm{H}_{1}$ ), we analysed the influence of different thresholds of $\mathrm{H}_{1}$ on $R_{N}$. As regional homogeneity is a fundamental prerequisite for applying PREC (see Castellarin et al., 2005; Castellarin, 2007), we considered two different thresholds, $\mathrm{H}_{1}<1$ and $\mathrm{H}_{1}<2$, that according to Hosking and Wallis (1997) refer to "acceptably homogeneous" and "possibly heterogeneous" regions, in this order. Following the main hypotheses for applying PREC, we did not consider larger thresholds (i.e. larger heterogeneity degrees).

\section{Study area and data}

The federal state of Saxony in the south-eastern Germany has a size of about $18400 \mathrm{~km}^{2}$ and is characterised by higher elevations in the Southwest (Erzgebirge) and lower elevations in the northern parts (Fig. 2). The Elbe is the largest river with a catchment size of about $52000 \mathrm{~km}^{2}$ at Dresden gauge. There are five large catchments in Saxony (Weisse Elster, Mulde, Schwarze Elster, Spree and Lausitzer Neisse, from west to east) and several tributaries to the River Elbe (Western and Eastern tributaries) (Fig. 2).

We only used gauges that (1) had a time series of more than 29 years, (2) were not strongly influenced by mining activities, (3) had a catchment size larger than $10 \mathrm{~km}^{2}$, and (4) were not located directly downstream of a dam. Furthermore, we omitted gauges whose catchments were mostly outside of Saxony. Ultimately, we considered 89 gauges as indicated in Fig. 2. Most of the gauges have a few nested catchment relationships. Nested catchment structures are especially located in the Mulde catchment. All tributaries of the Mulde catchments originating in the Erzgebirge are related to the two most downstream gauges (sites 34-35 in Fig. 2).

We derived the annual maxima series (AMS) as well as the highest observed discharge, the flood of record $Q_{\mathrm{FOR}}$, for all gauges. The suitability of the GEV as parent distribution for the 89 gauges was checked by a L-moment ratio diagram (see e.g. Vogel et al., 1993; Peel et al., 2001). It clearly stated that the use of the GEV was adequate.

Climatic, geologic and land-use data were used to derive catchment descriptors as basis for pooling catchments into homogeneous regions. Precipitation data was provided by the German Weather Service (DWD). We estimated precipitation indices from 453 stations in and around Saxony which had a record length of at least 30 years and still existed in 2002. We selected this year because of a severe wide-spread flood which occurred in 2002, in particular along the Elbe 
Table 1. List of catchment descriptors.

\begin{tabular}{ll}
\hline Abbreviation & Catchment descriptors \\
\hline MAP & Mean annual precipitation [mm] \\
MAXDAY & Maximum daily precipitation [mm] \\
P50 & Annual frequency of days with precipitation of more than $50 \mathrm{~mm} / \mathrm{d}[\%]$ \\
MAX5DAY & Maximum precipitation in five days [mm] \\
PAMS & Mean of the annual maximum series of daily precipitation [mm] \\
ELEV & Mean elevation of the catchment [m] \\
SLOPE & Mean slope of the catchment [\%] \\
RANGE_NORM & Range of catchment elevation, normalised with the catchment size $\left[10^{-3} \mathrm{~m}^{-1}\right]$ \\
ARABLE & Fraction of arable land coverage [\%] \\
URBAN & Fraction of urban land coverage [\%] \\
MINING & Fraction of mining activities [\%] \\
BEDROCK & Fraction of bedrock areas [\%] \\
KF_LOW & Fraction of low permeability areas [\%] \\
\hline
\end{tabular}

and Mulde. During this flood the highest daily precipitation ever recorded in Germany was measured. Therefore it is important to include the precipitation values of this year, e.g. to calculate the maximum daily precipitation. Additional precipitation stations were used to calculate the maximum daily precipitation and the maximum five-day precipitation sum. To better cover the spatial variability of precipitation, we improved the spatial resolution of precipitation stations by adding precipitation time series shorter than thirty years when the flood of record of the downstream gauge occurred during the period covered by the shorter precipitation time series. This led to 23 additional precipitation stations (476 in total) which could be used to calculate the maximum daily precipitation and the maximum five-day precipitation sum. All precipitation indices were interpolated by ordinary kriging.

Mean elevation, mean slope and catchment centroids were derived from digital elevation models. In Saxony a grid size of $25 \mathrm{~m}$ was used, whereas the digital elevation model from the Shuttle Radar Topographic Mission (SRTM) with a grid size of $90 \mathrm{~m}$ (Jarvis et al., 2008) was resampled to a grid size of $25 \mathrm{~m}$ for the areas outside of Saxony. Catchment centroids were required for the optimisation of the cross-correlation function (see Eq. 2). Furthermore, landscape parameters were derived from the digital landscape model ATKIS (BKG GeoDataCentre, 2005) and hydrogeological parameters were taken from the hydrogeological map (HÜK200) by the Saxon State Agency of Environment and Geology. Altogether, 13 catchment descriptors were selected (Table 1).

\section{Results}

\subsection{Intersite correlation in the study area}

Figure 3 illustrates the variability of empirical correlation coefficients for pairs of annual flood sequences in the study area. The heterogeneity of the correlation pattern becomes apparent when comparing empirical correlation coefficients higher than 0.8 (e.g. Mulde gauges, sites 34-60 in Fig. 3), as well as very low correlation coefficients (e.g. Mulde vs. Spree gauges (sites 71-83)). The gauges of the Mulde catchment and the western tributaries to the Elbe River originating in the Erzgebirge are characterised by large empirical correlation coefficients also beyond their catchment boundaries. The correlation coefficients of neighbouring catchments are larger than coefficients across the catchment boundaries. This correlation pattern demonstrates that AMS of neighbouring catchments are more correlated. Among the 3916 possible pairs of catchments, there are 179 nested (5\%) and 3737 unnested ones.

\subsection{Cross-correlation functions}

The cross-correlation function (Eq. 2) was optimised for global, nested and unnested catchment relationships. The different parameter sets for the cross-correlation function are given in Table 2. The parameters for the global and unnested cases are similar, whereas the parameters for nested catchments are noticeably different.

The relationship of the correlation coefficient to the distance of the catchment centroids for all pairs of sites shows that the correlation coefficients vary between -0.25 and 1 (Fig. 4). As expected, the correlation decreases with increasing distance. Due to the structure of the river network in Saxony, all distances between the centroids of nested catchments are lower than $50 \mathrm{~km}$, whereas unnested catchment 


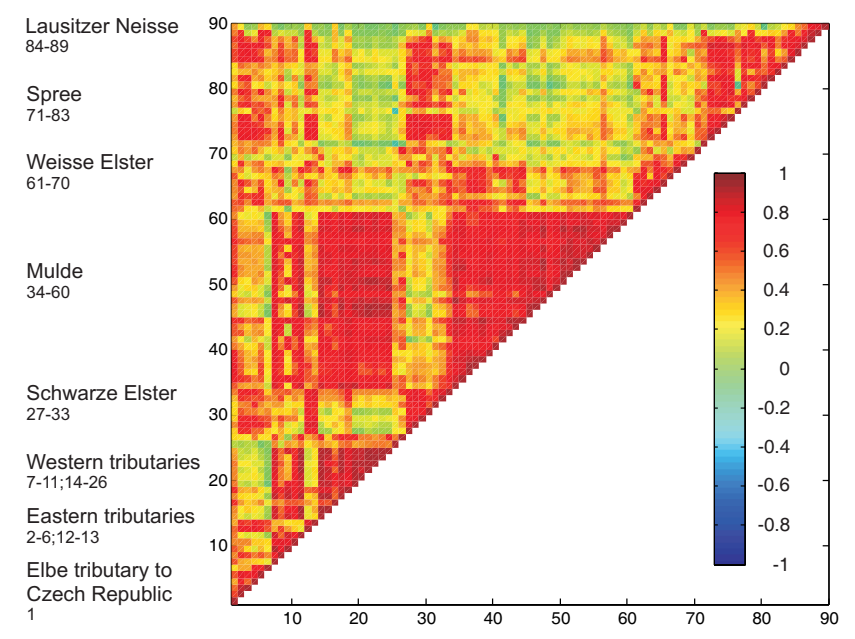

Fig. 3. Empirical cross-correlation coefficients for AMS of Saxon gauges.

relationships reach up to a distance of more than $200 \mathrm{~km}$. Figure 4 illustrates that the cross-correlation functions for the global and the unnested case are very similar, whereas the nested cross-correlation function strongly differs from them.

The global and the unnested cross-correlation functions clearly decrease up to a distance of about $50 \mathrm{~km}$ between the catchment centroids. The slope of the functions decreases slightly for larger distances. The differentiation in nested and unnested catchments shows a remarkable difference in terms of average cross-correlation. As expected, the crosscorrelation function for nested catchments yields higher correlations than the function for unnested ones, with differences of up to 0.2. To give an example, at a distance of $40 \mathrm{~km}$, there is a correlation coefficient of 0.7 for nested catchments, but only 0.5 for unnested catchments (Fig. 4).

The scattering in the correlation-distance plot (Fig. 4) illustrates that the distance between the catchment centroids is not the only relevant explanatory variable (see Troutman and Karlinger, 2003). However, the distance has a high explanatory power for this study area due to the significant decrease of the correlation coefficients with increasing distance.

\subsection{Region of influence}

20 candidate sets listed in Table 3 met the criteria of the pooling scheme (see Sect. 2.3). They were used to construct Regions of Influence (RoI) and to derive the corresponding probabilistic regional envelope curves.

The RoI approach was applied to each of the 89 gauges separately, using the 20 candidate sets of catchment descriptors and the three different thresholds in the physiographical space. This led to a maximum possible number of 5340 pooling groups. The maximum number was not reached, since regions which were heterogeneous $\left(\mathrm{H}_{1}>2\right)$ or had a small number of sites within a RoI $(n<4)$ were omitted. Ultimately,
Table 2. Parameters $\left(\lambda_{1}, \lambda_{2}\right)$ of the cross-correlation function by Tasker and Stedinger (1989) and available sample size (m) for different catchment structures.

\begin{tabular}{lrrr}
\hline & Global & Nested & Unnested \\
\hline$\lambda_{1}$ & 0.021 & 0.012 & 0.022 \\
$\lambda_{2}$ & 0.009 & 0.012 & 0.011 \\
$\mathrm{~m}$ & 3916 & 179 & 3737 \\
\hline
\end{tabular}

Table 3. Subsets of catchment descriptors (CD) and the correlation coefficient (COR) to the index flood of the annual maxima series of all gauges.

\begin{tabular}{llll}
\hline CD1 & CD2 & CD3 & COR \\
\hline MAX5DAY & ELEV & RANGE_NORM & 0.70 \\
MAX5DAY & RANGE_NORM & URBAN & 0.69 \\
MAP & MAX5DAY & RANGE_NORM & 0.69 \\
MAX5DAY & RANGE_NORM & & 0.68 \\
MAX5DAY & ELEV & URBAN & 0.68 \\
ELEV & RANGE_NORM & URBAN & 0.66 \\
PAMS & RANGE_NORM & URBAN & 0.64 \\
MAX5DAY & ELEV & & 0.64 \\
ELEV & RANGE_NORM & & 0.64 \\
MAP & MAX5DAY & URBAN & 0.64 \\
MAP & MAX5DAY & & 0.62 \\
MAP & RANGE_NORM & & 0.62 \\
PAMS & RANGE_NORM & & 0.62 \\
P50 & RANGE_NORM & URBAN & 0.61 \\
MAX5DAY & ARABLE & URBAN & 0.61 \\
MAXDAY & RANGE_NORM & URBAN & 0.61 \\
MAX5DAY & URBAN & BEDROCK & 0.61 \\
MAX5DAY & PAMS & URBAN & 0.61 \\
RANGE_NORM & URBAN & BEDROCK & 0.60 \\
RANGE_NORM & BEDROCK & & 0.60 \\
\hline
\end{tabular}

1415 pooling groups with on average 13 sites fulfilled the assumption of the PREC concept and were used further.

\subsection{Influence of intersite correlation on information content}

The number of effective observations was calculated for all 1415 pooling groups with the global parameter set $\left(n_{\mathrm{eff}, G}\right)$ for the cross-correlation function as well as with the separate parameter sets for nested and unnested catchment structures $\left(n_{\text {eff, } N}\right)$. Figure 5 illustrates that, as it is expected, the number of effective observations is lower than the number of total observations for all pooling groups. It further indicates that the ratio of the number of effective observations to the number of total observations - information contents $\mathrm{IC}_{G}$ (global approach) and $\mathrm{IC}_{N}$ (nested-unnested approach) - decreases as the number of total observations increases. To give an example, while the information content is about 0.5 for data 


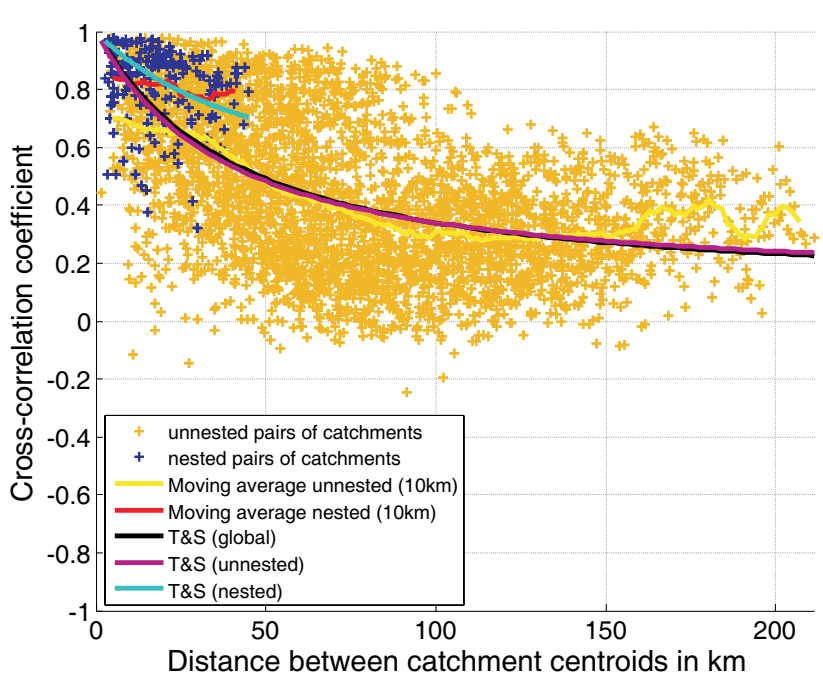

Fig. 4. Cross-correlation functions fitted to global, unnested and nested catchment structures (T\&S: cross-correlation function by Tasker and Stedinger, 1989).

sets with 600 total observations, it decreases to only 0.3 in the case of 2000 total observations.

These results show how the information content decreases when an additional site is added. The larger the number of sample years of data, the lower is the additional gain of information by adding one site to the pooling group. Furthermore, the additional gain of information is lower for nested catchments. Hence, the reduction effect of cross-correlated sites on $n_{\text {eff }}$ becomes larger as the number of total observations $n$ increases.

\subsection{Recurrence interval}

While a comparison of the effective sample years of data to the total sample years of data already illustrates the effect of intersite correlation on the information content, the recurrence interval $T$ of PREC shows this effect more clear, since $T$ is directly related to flood quantile estimates (see Eq. 6).

A comparison of $T_{G}$ and $T_{N}$ reveals that the recurrence interval is higher in most cases when the global crosscorrelation function is used (Fig. 6). The range of the ratio $R_{N}$ is between -23 and $3 \%$ (Fig. 7a). In other words, the recurrence interval is up to $23 \%$ lower when using separate parameter sets for nested and unnested catchment relationships. The difference increases with increasing recurrence intervals (Fig. 6), but the ratio $R_{N}$ does not show a distinct relation to the recurrence interval (Fig. 7a).

\subsection{Degree of nesting}

The calculation of $T_{G}$ differs from $T_{N}$ only in the parameter set for the cross-correlation function. Since there are large differences between the parameter sets for nested catchments on the one hand and for unnested catchments and the global

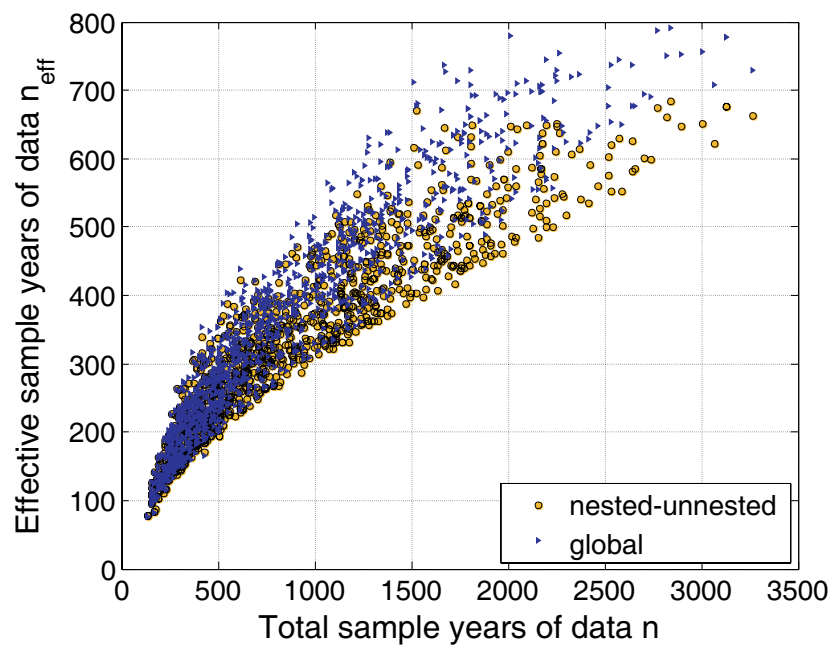

Fig. 5. Number of effective observations vs. sample years of data within the pooling groups for a global cross-correlation function and separate cross-correlation functions for nested and unnested catchments.

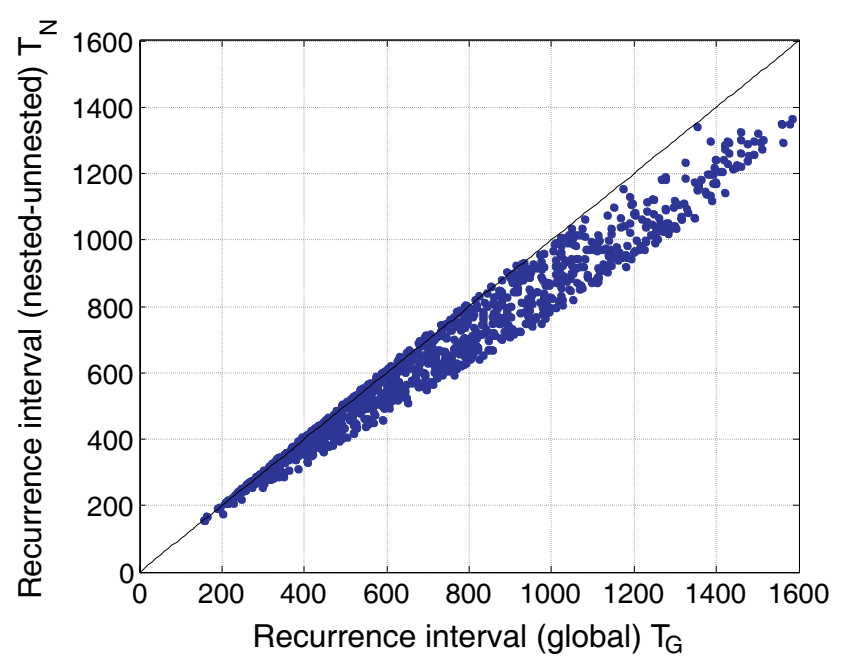

Fig. 6. Difference in recurrence intervals between a single crosscorrelation function (global) and separated cross-correlation functions (nested-unnested).

approach on the other hand (see Table 2), it is interesting to look at the nested catchment structure in the study area. Therefore the ratio $R_{N}$ is related to the degree of nesting $D_{N}$, i.e. the relative number of nested catchments within a pooling group (see Eq. 8). It is expected that $R_{N}$ is mainly affected in pooling groups with a large degree of nesting.

$R_{N}$ decreases with a higher degree of nesting (Fig. 7b). There is a particularly strong decrease of $R_{N}$ for $D_{N}$ between 0 and 0.2. This implies that even a small degree of nesting affects the recurrence interval of the PREC appreciably. However, a certain degree of nesting is required to estimate large differences between the recurrence intervals 

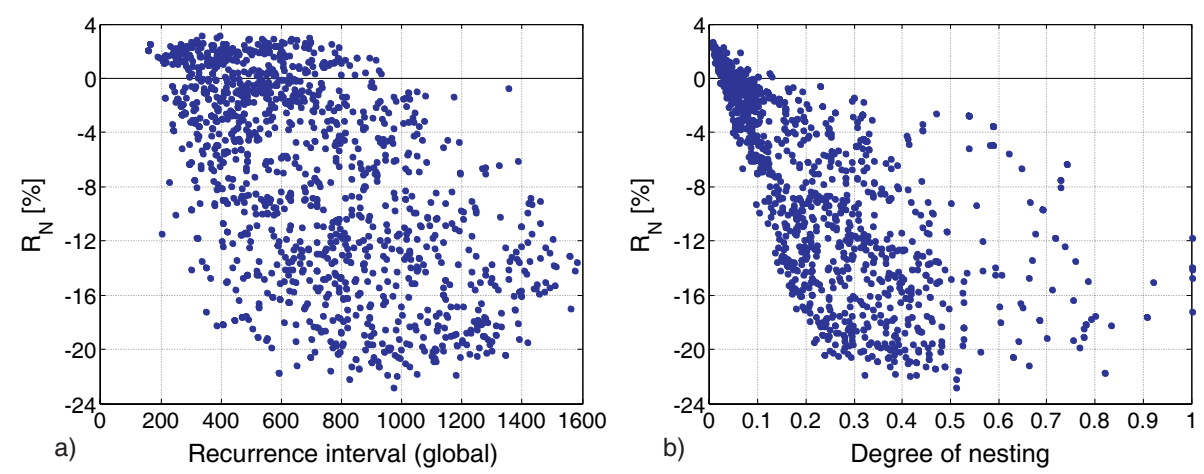

Fig. 7. Ratio of recurrence interval $R_{N}$ vs. the recurrence interval estimated by a global cross-correlation function $T_{G}$ (a) and degree of nesting $D_{N}$ (b).

for the global $T_{G}$ and the nested-unnested approach $T_{N}$. For example, $R_{N}<-10$ is observed for $D_{N}>0.1$. $R_{N}$ decreases up to a degree of nesting of about 0.4 .

Positive values of $R_{N}$ are observed for a degree of nesting lower than 0.15 and therefore for pooling groups without or with only a few nested catchments. In the most extreme case $\left(D_{N}=0\right)$, the parameter set for unnested catchment relationships is always used in the nested-unnested approach. Figure 4 has shown that the cross-correlation function for unnested catchments leads to the smallest correlation values. Consequently the correlation among sites is lower if only unnested catchments were used compared with the global approach using all catchments. Hence, the lower correlation between unnested catchments leads to a higher recurrence interval $\left(T_{N}>T_{G}\right)$ resulting in a positive value of $R_{N}$ (see Eq. 7).

\subsection{Different thresholds of the heterogeneity measure}

The threshold of the heterogeneity measure was varied to investigate the effect on the formation of pooling groups and, in particular, on the recurrence interval of the PREC. The procedure for $\mathrm{H}_{1}<2$ was repeated for $\mathrm{H}_{1}<1$. A lower threshold of the heterogeneity measure leads to less pooling groups and thus to less realisations of PRECs.

The comparison of the ratio $R_{N}$ with $T_{G}$ reveals that $R_{N}$ decreases with increasing $T_{G}$ for both thresholds of the heterogeneity measure (Fig. 8). This relationship is illustrated in equidistant intervals of the recurrence intervals. We only show the results for cases with more than ten pooling groups within the equidistant interval. The number of pooling groups decreases for a lower threshold because of the stricter homogeneity criterion. While different thresholds for the heterogeneity measure lead to a different number of pooling groups, and therefore affect the results, they do not influence the general statements.
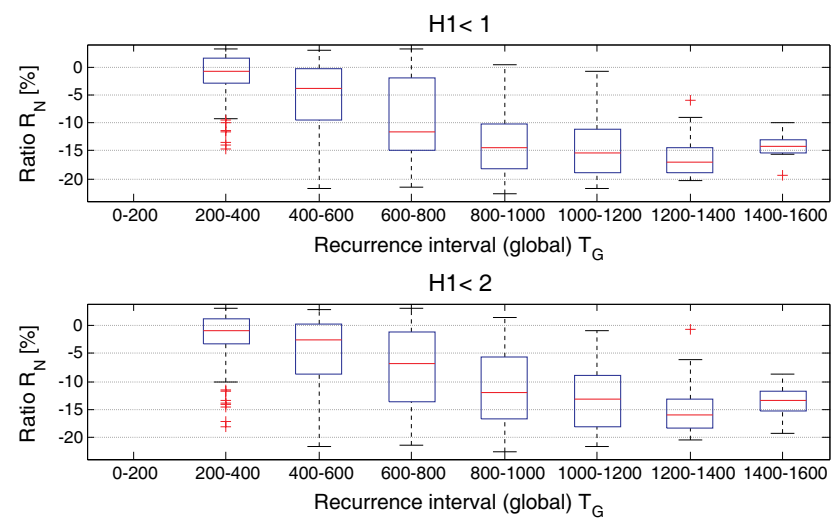

Fig. 8. Ratio of recurrence interval $R_{N}$ vs. the recurrence interval estimated by a global cross-correlation function $T_{G}$ for different thresholds of the heterogeneity measure.

\section{Discussion}

Our goal was to estimate the impact of the intersite dependence of nested catchment structures on the effective sample years of data and the recurrence interval of PREC. Therefore, nested and unnested pairs of catchments were treated with separate parameter sets for the cross-correlation function. This enabled us to compare the nested approach with the traditional one using a global cross-correlation function.

There are three interesting aspects to discuss. These are (1) the differences between the three cross-correlation function applications (global, nested, unnested); (2) the link of a differentiation in nested and unnested catchments to different hydrologic situations, and (3) the impact of the two different approaches of the cross-correlation function (global vs. nested-unnested) on the effective sample years of data and the recurrence interval derived by PRECs and its relevance for this study area.

The heterogeneity in the correlation matrix (see Fig. 3) leads to a scattering of the empirical correlation coefficients in relationships to the distance (see Fig. 4). Madsen and 
Rosbjerg (1997a) determined a scattering due to the heterogeneity of the region. Whereas we separated the catchment relationships into nested and unnested catchment relationships, Madsen and Rosbjerg (1997a) divided the study area in two regions and estimated separate regional correlation functions for each region. By doing so, they estimated that a separate consideration of two regions led to a larger average intersite correlation than an overall approach. In our study, we also estimated larger intersite correlations for the nestedunnested approach than for the global approach for most of the pooling groups. A lower intersite correlation is found for the nested-unnested approach in specific cases (e.g. a low degree of nesting)

Figure 4 demonstrates that there is a large decrease of the cross-correlation functions for the unnested and global approaches up to a distance of about $50 \mathrm{~km}$. Merz and Blöschl (2003) assumed that catchments whose centroids have a distance less than $50 \mathrm{~km}$ are frequently affected by the same event, resulting in a relatively large correlation between their flood sequences. Catchments with larger distances are affected by different events, and consequently the discharge time series are less correlated.

The relevance of separate parameter sets for the crosscorrelation function for nested and unnested catchments depends on the spatial extent of floods and consequently on the prevailing flood regime. Large-scale precipitation events may lead to larger intersite correlations than local convective rainfalls. In regions that are mainly influenced by long precipitation events, widespread floods may occur at neighbouring gauges across catchment boundaries, independently of the catchment structure. In this case, the gauges might be correlated beyond catchment boundaries (Merz and Blöschl, 2003), and it is expected that there are only limited differences between the correlation relationships within and across catchment boundaries. It is assumed that especially large floods across wide areas lead to a large correlation between catchments (Hosking and Wallis, 1988), implying that high flood quantiles are affected stronger by intersite correlation. This statement coincides with the decrease in the regional information content with increasing sample years of data (see Fig. 5).

An opposite situation is given for flood regimes that are dominated by local convective precipitation events with small spatial extent. A local precipitation event might evoke a flash flood only along the river. Then, only a few catchments, in particular nested catchments, are affected by the same flash flood and low correlation relationships across catchment boundaries are expected. In this case, the impact of a separation in nested and unnested catchment relationships might be strong.

In our study area, Saxony, both local floods (e.g. in 1927, 1957) as well as regional wide-spread floods (e.g. in 1954, 1958, 2002) occurred in the past (e.g. Pohl, 2004; Petrow et al., 2007). The rivers of the Erzgebirge, specifically the headwaters of the Mulde river and in particular the western tributaries of the Elbe river, were affected by flash floods (e.g. Ulbrich et al., 2003), which in Saxony occur mostly in July and August. These floods produce the highest unit flood discharges in the study area. Due to the fast catchment response in the Erzgebirge, downstream gauges are directly affected by flash floods. In this context it is necessary to mention that the western tributaries of the Elbe are relatively small tributaries with only up to three gauges, whereas there are several nested relationships among the gauges of the Mulde catchment (see Fig. 2).

Since no gauges located at the River Elbe, the largest river in the study area, are included in the analysis, the differences between the catchment sizes of nested catchments are not too large. This aspect is especially important for this study area, since most of the largest floods occurred in the western tributaries of the River Elbe. These rivers flow into the Elbe upstream of the gauge Dresden. Because of their relatively small catchment sizes $\left(<200 \mathrm{~km}^{2}\right)$ in comparison to the Dresden gauge $\left(52000 \mathrm{~km}^{2}\right)$, it is not expected that the mean discharge at gauge Dresden is significantly influenced by a local flood in one of the western tributaries only.

In the study area, there are only 5\% of pairs of nested catchments. As expected, this study has shown significantly larger correlation among nested catchments than unnested ones. The effect of a distinction in nested and unnested crosscorrelation functions might be even larger in regions with a larger number of nested catchment relationships. However, $5 \%$ of pairs of nested catchments lead to a significant reduction in the recurrence interval of PREC.

In this study, only one specific point of the PREC method is assessed. It is clear that the recurrence interval of PREC is affected by all steps of the PREC method. However, to determine the influence of one particular step in the PREC concept, it is necessary that all other aspects are constant. This was realised in this study by emphasising the selection of the parameter sets for the cross-correlation function in a hydrologically more comprehensive way.

The introduction of the nested structure to the PREC concept results in a reduction of the recurrence interval of up to $23 \%$ (see Fig. 7). Therefore, it is recommended to use different cross-correlation functions for nested and unnested catchments, in particularly for pooling groups with a large degree of nesting (see Fig. 7b). In this study, there is a relevant effect for a degree of nesting larger than 0.15 .

\section{Conclusions}

This study focused on the modelling of intersite dependence when estimating the recurrence interval of a probabilistic regional envelope curve (PREC). A correct representation of the intersite dependence is fundamental for quantifying the regional information content of a pooling group, and therefore also for identifying the effective sample years of data, which is a key step of the PREC concept. The regional 
information content is defined as the ratio between the effective sample years of data (i.e. equivalent number of independent observations) and the overall sample years of data in the regional sample.

The analysis clearly shows that the intersite correlation for nested pairs of catchments is significantly larger than for unnested pairs, suggesting separate cross-correlation functions for nested and unnested pairs of catchments. A separation into nested and unnested pairs of catchments while modelling the intersite dependence represents an innovation and a refinement of the existing approach.

The study adopts a cross-correlation function whose parameters are identified for the whole study area (traditional approach) as well as differentiated between nested and unnested catchment pairs (proposed approach). The main outcomes can be summarised as follows:

1. the differentiation in cross-correlation functions for nested and unnested pairs of catchment enables one to improve the estimates of the number of effective observations;

2. in most of the cases, the number of effective observations and, therefore, the recurrence interval of PREC, are reduced by modelling the intersite dependence for pairs of nested and unnested catchments separately;

3 . the reduction of the estimated recurrence interval increases with the size of the pooling group, or, evidently, with a higher degree of nesting in the pooling group of sites;

4. the results of the analysis are valid for different degrees of heterogeneity of the pooling group of sites. Defining the heterogeneity of the pooling groups in terms of $\mathrm{H}_{1}$-values as proposed by Hosking and Wallis (1993), the study shows that the same considerations that are valid for possibly heterogeneous pooling groups of sites $\left(\mathrm{H}_{1}<2\right)$ still hold for acceptably homogeneous groups $\left(\mathrm{H}_{1}<1\right)$.

Because of the effect of nested catchment structures on the recurrence interval of PREC, we recommend to apply different cross-correlation functions for nested and unnested catchments in PREC studies. Our study points out that the effect of nested structure becomes relevant for regions in which the number of nested pairs of catchments is larger than $15 \%$ of the total number of pairs. Separate cross-correlation functions reflect the characteristic catchment structure and incorporate this structure in the estimation of flood quantiles.

Acknowledgements. We thank the three anonymous referees for their very useful comments and their helpful recommendations to our manuscript in HESSD.
This work is part of the Center for Disaster Management and Risk Reduction Technology (CEDIM) (http://www.cedim.de), a joint venture between the Helmholtz Centre Potsdam - GFZ German Research Centre for Geosciences, the Technical University of Karlsruhe (TH) and the Forschungszentrum Karlsruhe. We thank CEDIM and the GFZ and the University of Bologna for the financial support. Attilio Castellarin acknowledges the Italian Ministry of Education for the grant no. 2007HBTS85_003.

We thank the State Agency of Environment and Geology of the Free State of Saxony for the permission to use the discharge data and the hydrogeological map (HÜK 200) (http://www.umwelt.sachsen.de/umwelt/geologie/7703.htm, 5 February 2007). Furthermore, we thank the State Agency of Flood Prevention and Water Management of Saxony-Anhalt and the State Agency for Environment of Thuringia for additional discharge data. We also thank the Potsdam Institute for Climate Impact Research (PIK) and the German Weather Service (DWD) for precipitation data as well as the Federal Agency for Cartography and Geodesy of Germany (BKG) for the ATKIS-Basis-DLM and the digital elevation model for Saxony. We also thank the European Commission - Joint Research Centre (JRC) for the CCM River and Catchment Database. The SRTM Digital Terrain Model was downloaded from (http://srtm.csi.cgiar.org/SELECTION/inputCoord.asp, 19 May 2008).

Edited by: M. Sivapalan

\section{References}

Acreman, M. C. and Sinclair, C. D.: Classification of drainage basins according to their physical characteristics: an application for flood frequency analysis in Scotland, J. Hydrol., 84(3), 365380, 1986.

BKG Geodatenzentrum (Federal Agency for Cartography and Geodesy - GeoDataCentre): Digital Landscape Model ATKIS Basis DLM, Frankfurt/Main, 2005.

Burn, D. H.: An appraisal of the "region of influence" approach to flood frequency analysis, Hydrolog. Sci. J., 35(2), 149-165, 1990a.

Burn, D. H.: Evaluation of Regional Flood Frequency Analysis with a Region of Influence Approach, Water Resour. Res., 26(10), 2257-2265, 1990b.

Castellarin, A.: Probabilistic envelope curves for design flood estimation at ungauged sites, Water Resour. Res., 43(4), W04406, doi:10.1029/2005WR004384, 2007.

Castellarin, A., Burn, D. H., and Brath, A.: Assessing the effectiveness of hydrological similarity measures for flood frequency analysis, J. Hydrol., 241(3), 270-285, 2001.

Castellarin, A., Burn, D. H., and Brath, A.: Homogeneity testing: How homogeneous do heterogeneous cross-correlated regions seem?, J. Hydrol., 360(1-4), 67-76, 2008.

Castellarin, A., Vogel, R. M., and Matalas, N. C.: Probabilistic behaviour of a regional envelope curve, Water Resour. Res., 41, W06018, doi:10.1029/2004WR003042, 2005.

Castellarin, A., Vogel, R. M., and Matalas, N. C.: Multivariate probabilistic regional envelopes of extreme floods, J. Hydrol., 336(34), 376-390, 2007. 
Crippen, J. R. and Bue, C. D.: Maximum Flood Flows in the Conterminous United States, Geological Survey Water-Supply Paper 1887, United States Printing Office, Washington DC, 1977.

Cunnane, C.: Methods and Merits of Regional Flood Frequency Analysis, J. Hydrol., 100(1-3), 269-290, 1988.

Dalrymple, T.: Flood frequency analyses, US Geol. Surv. Water Supply Pap.: 1543-A, 1960.

Gaál, L. and Kyselý, J.: Regional frequency analysis of heavy precipitation in the Czech Republic by improved region-of-influence method, Hydrol. Earth Syst. Sci. Discuss., 6, 273-317, 2009, http://www.hydrol-earth-syst-sci-discuss.net/6/273/2009/.

GREHYS: Inter-comparison of regional flood frequency procedures for Canadian rivers, J. Hydrol., 186(1-4), 85-103, 1996a.

GREHYS: Presentation and review of some methods for regional flood frequency analysis, J. Hydrol., 186(1-4), 63-84, 1996b.

Herschy, R.: The world's maximum observed floods, Flow Meas. Instrum., 13, 231-235, 2002.

Hirsch, R. M., Helsel, D. R., Cohn, T. A., and Gilroy, E. J.: Statistical analysis of hydrological data, in: Handbook of Hydrology, edited by: Maidment, D. A., McGraw-Hill, New York, 17.1$17.55,1992$.

Hosking, J. R. M. and Wallis, J. R.: The effect of intersite dependence on regional flood frequency analysis, Water Resour. Res., 24(4), 588-600, 1988.

Hosking, J. R. M. and Wallis, J. R.: Some statistics useful in regional frequency analysis, J. Hydrol., 29(2), 271-281, 1993.

Hosking, J. R. M. and Wallis, J. R.: Regional frequency analysis: an approach based on L-moments, Cambridge University Press, Cambridge, UK, 1997.

Jarvis, A., Reuter, H. I., Nelson, A., and Guevara, E.: Hole-filled SRTM for the globe Version 4, available from the CGIAR-CSI SRTM 90 m Database: http://srtm.csi.cgiar.org, 2008.

Kjeldsen, T. R. and Rosbjerg, D.: Comparison of regional index flood estimation procedures based on the extreme value type I distribution, Stoch. Env. Res. Risk A., 16(5), 358-373, 2002.

Kjeldsen, T. R. and Jones, D. A.: Prediction uncertainty in a median-based index flood method using L moments, Water Resour. Res., 42, W07414, doi:10.1029/2005WR004069, 2006.

Kroll, C. N. and Stedinger, J. R.: Regional hydrologic analysis: Ordinary and generalized least squares revisted, Water Resour. Res., 34(1), 121-128, 1998.

Kuczera, G.: Effect of sampling uncertainty and spatial correlation on an empirical Bayes procedure for combining site and regional information, J. Hydrol., 65(4), 373-398, 1983.

Madsen, H. and Rosbjerg, D.: Generalized least squares and empirical Bayes estimation in regional partial duration series indexflood modelling, Water Resour. Res., 33(4), 771-781, 1997a.

Madsen, H. and Rosbjerg, D.: The partial duration series method in regional index-flood modelling, Water Resour. Res., 33(4), 737746, $1997 b$.

Matalas, N. C. and Langbein, W. B.: Information content of the mean, J. Geophys. Res., 67(9), 3441-3448, 1962.

Merz, R. and Blöschl, G.: A process typology of regional floods, Water Resour. Res., 39(12), 1340, doi:10.1029/2002WR001952, 2003

Merz, R. and Blöschl, G.: Flood frequency regionalisation - spatial proximity vs. catchment attributes, J. Hydrol., 302(1-4), 283306, 2005.

Nathan, R. J. and McMahon, T. A.: Identification of homogeneous regions for the purposes of regionalization, J. Hydrol., 121(1-4), 217-238, 1990.

Ouarda, T. B. M. J., Bâ, K. M., Diaz-Delgado, C., Cârsteanu, A., Chokmani, K., Gingras, H., Quentin, E., Trujillo, E., and Bobée, B.: Intercomparison of regional flood frequency estimation methods at ungauged sites for a Mexican case study, J. Hydrol., 348(1-2), 40-58, 2008.

Peel, M. C., Wang, Q. J., Vogel, R. M., and McMahon, T. A.: The utility of L-moment ratio diagrams for selecting a regional probability distribution, Hydrolog. Sci. J., 46(1), 147-156, 2001.

Petrow, Th., Merz, B., Lindenschmidt, K.-E., and Thieken, A. H.: Aspects of seasonality and flood generating circulation patterns in a mountainous catchment in south-eastern Germany, Hydrol. Earth Syst. Sci., 11, 1455-1468, 2007, http://www.hydrol-earth-syst-sci.net/11/1455/2007/.

Pohl, R.: Historische Hochwasser aus dem Erzgebirge, Wasserbauliche Mitteilungen, Heft 28, Fakultät Bauingenieurwesen, Institut für Wasserbau und Technische Hydromechanik, Technische Universität Dresden, Dresden, 2004.

Rao, R. and Srinivas, V. V.: Regionalization of watersheds by hybrid-cluster analysis, J. Hydrol., 318(1-4), 37-56, 2006.

Reis Jr., D. S., Stedinger, J. R., and Martins, E. S.: Bayesian generalized least squares regression with application to log Pearson type 3 regional skew estimation, Water Resour. Res., 41, W10419, doi:10.1029/2004WR003445, 2005.

Robson, A. and Reed, D.: Flood Estimation Handbook 3: Statistical procedures of flood frequency estimation, Institute of Hydrology, Wallingford/UK, 338 pp., 1999.

Rosbjerg, D. and Madsen, H.: Uncertainty measures of regional flood frequency estimators, J. Hydrol., 167(1-4), 209-224, 1995.

Skøien, J. O., Merz, R., and Blöschl, G.: Top-kriging - geostatistics on stream networks, Hydrol. Earth Syst. Sci., 10, 277-287, 2006 , http://www.hydrol-earth-syst-sci.net/10/277/2006/.

Stedinger, J. R.: Estimating a Regional Flood Frequency Distribution, Water Resour. Res., 19(2), 503-510, 1983.

Stedinger, J. R. and Lu, L.: Appraisal of regional and index flood quantile estimators, Stoch. Hydrol. Hydraul., 9(1), 49-75, 1995.

Stedinger, J. R. and Tasker, G. D.: Regional hydrologic analysis, 1 , Ordinary, weighted, and generalised least squares compared, Water Resour. Res., 21(9), 1421-1432, 1985.

Stedinger, J. R. and Tasker, G. D.: Regional hydrologic analysis, 2, Model-error estimators, estimation of sigma and log-Pearson type 3 distributions, Water Resour. Res., 22(10), 1487-1499, 1986.

Stedinger, J. R., Vogel, R. M., and Foufoula-Georgiou, E.: Frequency Analysis of extreme events, in: Handbook of Hydrology, edited by: Maidment, D. A., McGraw-Hill, New-York, 18.118.66, 1993.

Tasker, G. D. and Stedinger, J. R.: An operational GLS model for hydrologic regression, J. Hydrol., 111(1-4), 361-375, 1989.

Troutman, B. M. and Karlinger, M. R.: Regional flood probabilities, Water Resour. Res., 39(4), 1095, doi:10.1029/2001WR001140, 2003.

Ulbrich, U., Brücher, T., Fink, A. H., Leckebusch, G. C., Krüger, A., and Pinto, J. G.: The central European floods of August 2002: part 1 - Rainfall periods and flood development, Weather, 58, 371-377, 2003.

Viglione, A.: The nsRFA Package, r package version 0.4-8, 2008 
Vogel, R. M. and Fennessey, N. M.: L Moment Diagrams Should Replace Product-Moment Diagrams, Water Resour. Res., 29(6), 1745-1752, 1993.

Vogel, R. M., Zafirakou-Koulouris, A., and Matalas, N. C.: Frequency of record-breaking floods in the United States, Water Resour. Res., 37(6), 1723-1731, 2001.
Vogt, J. V., Soille, P., de Jager, A., Rimavičiūté, E., Mehl, W., Foisneau, S., Bódis, K., Dusart, J., Paracchini, M. L., Haastrup, P., and Bamps, C.: A pan-European River and Catchment Database, European Commission, EUR 22920 EN - Joint Research Centre, 2007.

Zrinji, Z. and Burn, D. H.: Flood frequency analysis for ungauged sites using a region of influence approach, J. Hydrol., 153(1-4), 1-21, 1994. 